\title{
GSM/GPS based toll collection system - proposal for Poland
}

\author{
G. Nowacki, I. Mitraszewska \& T. Kamiński \\ Management and Transport Telematics Centre, \\ Motor Transport Institute, Warsaw, Poland
}

\begin{abstract}
The paper refers to some problems in worldwide applications of electronic toll collection systems for motorways and expressways. According to the Directive 2004/52/EC, these systems should use one or more of the following technologies: satellite positioning, mobile communications using the GSMGPRS standard (reference GSM TS 03.60/23.060) and 5, $8 \mathrm{GHz}$ microwave technology. Authors have analyzed systems which meet these requirements, especially in the following countries: The United State of America, Japan, Taiwan, Australia, Austria, Czech Republic, France and Germany. As a result of the analysis, it has turned out that only a system using satellite positioning technology and mobile communications (GSM/GPRS) is the best toll solution of unique capabilities and this kind of technologically sophisticated system should be implemented in Poland. Authors will present the initial structure of GSM/GPS based Toll Collection System for Poland.

Keywords: electronic toll collection (ECT), microwave technology, on-board unit $(O B U)$.
\end{abstract}

\section{Introduction}

Electronic Toll Collection (ETC) is a fairly mature technology that allows electronic payment for motorways and expressways. An ETC system is capable to determine if a car is registered in a toll payment program, alerts enforcers of toll payment violations, and debits the participating account. ETC is fast becoming a globally accepted method of toll collection, a trend greatly aided by the growth of interoperable ETC technologies.

All new electronic toll collection systems brought into service on or after 1 January 2007 shall, for carrying out electronic toll transactions, use one or more 
of the following technologies: satellite positioning, mobile communications using the GSM-GPRS standard (reference GSM TS 03.60/23.060) and 5,8 GHz microwave technology.

The above mentioned conditions are included in the Directive 2004/52/EC of the European Parliament and of the Council of 29 April 2004 on the interoperability of electronic road toll systems in the Community [1].

The requirements of that directive will be implemented in Poland based on the Act from 7 of November 2008 and some other acts [2]. It stressed that toll collecting charge institutions should be able to carry out electronic toll transactions from 1 of July 2011.

New electronic toll systems brought into service after the adoption of this Directive should use the satellite positioning and mobile communications technologies. The Working Group No 1 (WG1) of Technical Committee 278 (Road Transport and Traffic Telematics) established in 1991 is responsible for electronic toll collection systems in European Union. ISO/TC 204 is the partner of CEN/TC 278 in ISO, responsible for the international standardisation of transport information, communication and control systems. It is recommended to implement National Automated Toll System for highways and expressways in Poland. Authors have carried out the analysis of some systems functioning all over the world to chose the best one for Poland.

\section{Characterization of electronic toll collection systems}

DSRC (Dedicated Short range Communication) is typically used as the primary method of charging where a charge is to be applied at one of a discrete number of specific points, such as a toll plaza (an area where tollbooths are located) or a location on the open highway.

The Rationale for Electronic Toll Collection ETC systems take advantage of vehicle-to-roadside communication technologies (traditionally via microwave or infrared communication, more recently via GPS technology) to perform an electronic monetary transaction between a vehicle passing through a toll station and the toll agency.

Electronic Toll Road Systems in USA and some European Member States using microwave technology have functioned independently. The telematics systems are implemented in some states, an example being Hitachi System (Japan), as well as Barouh System (Taiwan), which provide the function of electronic road toll for highways and expressways and additionally function of transferring data from digital tachographs. Toll Collecting System in Germany is a modern solution for the mentioned scope.

\subsection{Electronic tall collection systems using microwave technology - DSRC}

Electronic Toll System using microwave technology is an element of ITS that allows for nonstop toll collection and traffic monitoring. It is to uniquely identify each vehicle, electronically collect the toll, provide general vehicle/traffic monitoring and data collection. New technologies and infrastructures provide the 
necessary capabilities for future applications such as incident management, alternate route guidance, and travel demand management. Properly implemented, system can reduce congestion, increase operating efficiency, improve travel time, reduce pollution, and improve safety of the roadway facility and surrounding corridors. All electronic tall systems using microwave technology all over the world have the same structure, which utilize vehicles equipped with transponders (electronic tags), toll and control gantries, in-road/roadside detection and classification sensors, computerized system (hardware and software) and wireless communication $(5,8 \mathrm{GHz}$ nearly all over the world, only $5,9 \mathrm{GHz}$ in USA), as well as enforcement technologies.

The elements of toll system like transponders (tags) mounted on the vehicle's windshield, have got the same dimensions (cigarettes box), but for every kind of system the vehicle should be equipped with different transponder (fig. 1), for example Go-Box in Austria, Premid in Czech Republic, Passango in France. The antennas carried by gantries communicate with transponders (On Board Units, OBU). Users can get the OBU at a high number of points of sale 24 hours a day. $\mathrm{OBU}$ is equipped with a switch for the change of the vehicle class for instance in case of an additional trailer.

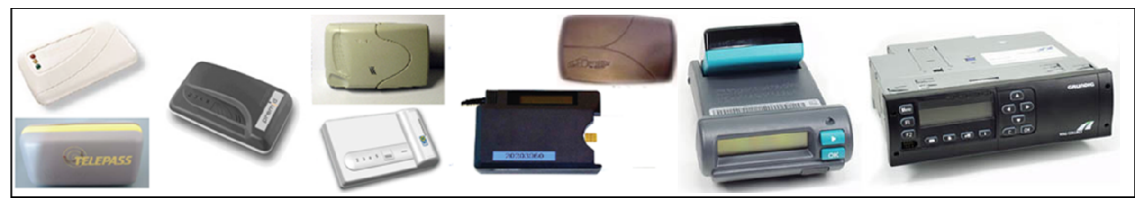

Figure 1: Electronic transponders mounted on the vehicle's windscreen.

In June 2002, ASFINAG (Autobahnen und Schnellstrassen-Finanzierung AG) Austria's national road authority charged with planning, financing, building and maintenance of the highway network, awarded a contract for the installation and operation of a fully electronic nationwide toll system for heavy goods vehicles with a maximum permissible laden weight of 3,5 tones to Autostrade S.p.A. with Kapsch TrafficCom AG [3] as the turn-key system supplier. The toll system is an open system with one gantry for toll communication in each sector between exit/entry-points. More than 800 gantries (420 for each driving direction) had been implemented in the entire network [4].

Users who rarely drive on the tolled road network can choose to pay the toll using the pre-paying procedure. This procedure is similar to that of a prepaid telephone card; the user charges the Go-Box with toll credit up to a certain maximum limit and the toll is then deducted from this credit as required by the toll system. According to this procedure, the owner of the vehicle registers with the system and provides an authorized means of payment, which is later used to pay the toll as required. The money is collected by the relevant card issuer (Maestro card, petrol card or credit card).

Electronic toll has been paid by vehicles weighing 12 tons and more on 970 km of motorways and express roads in the Czech Republic as of January 12007. Kapsch TrafficCom AB contracted the system in Czech Republic, but the 
transponder is different and called Premid. It is the brand name for a product line of microwave-based communication links for dedicated short range communication, DSRC, between fixed Roadside Equipment and mobile units. Kapsch TrafficCom AB has supplied this DSRC Link technology to a large number of traffic applications in over 20 countries all over the world.

The term TIS-PL refers to the new French electronic toll system for class 3 and 4 HGVs. Modelled on the "Liber-t" system designed for light vehicles in France, the TIS-PL is a badge which is fitted to the windscreen and which simplifies toll payments (motorways, tunnels, bridges etc.). Launched at the beginning of 2007, it has since replaced the CAPLIS toll card as the method of toll payment in France.

The tolls in the United States are typically collected using RFID (Radio Frequency Identification). It is an automatic identification method, relying on storing and remotely retrieving data using devices called RFID tags or transponders. An RFID tag is an object that can be attached to or incorporated into a product, animal, or person for the purpose of identification using radio waves. Chip-based RFID tags contain silicon chips and antennae. Passive tags require no internal power source, whereas active tags require a power source.

Example of mentioned system is the E-ZPass electronic toll collection system used on most toll bridges and toll roads in the eastern U.S. from Virginia to Maine, and recently extended into Illinois; Houston`s EZ Tag, which also works in other parts of the state of Texas, California's FasTrak, Illinois' I-Pass, Florida`s SunPass, and more recently Indiana`s I-Zoom. Traffic in these special lanes can move well with minimal slowing down. Toll roads have been only in 26 states as of 2006. The majority of states without any turnpikes are in the West and South [5, 6]. Operation principle of the system is the same in Europe (fig. 2).

As a car approaches a toll plaza, the radio-frequency (RF) field emitted from the antenna activates the transponder. The transponder broadcasts a signal back to the lane antenna with some basic information. That information is transferred from the lane antenna to the central database. If the account is in good standing, a toll is deducted from the driver's prepaid account. If the toll lane has a gate, the gate opens. A green light indicates that the driver can proceed. Some lanes have text messages that inform drivers of the toll just paid and their account balance. If the vehicle does not have a transponder, the system classifies it as a violator and cameras take photos of the vehicle and its license plate for processing. If the license plate is registered as belonging to toll system user, the account is debited with only the toll charge, and no penalty is charged.

Hitachi has developed creative solutions to roadside communications, traffic operation and payment processing to enhance toll collection system performance. Capable of high-speed operation to enable free traffic flow, the system incorporates a fully integrated payment processing system, comprising facilities to identify and record illegal passage, efficient management of tollcollection data, system auditing and access management for high security and EDI processing to facilitate smooth fund transfers. Hitachi covers everything from data collection to information delivery. Hitachi has made advanced system concepts a reality, with a complete information system consisting of data 


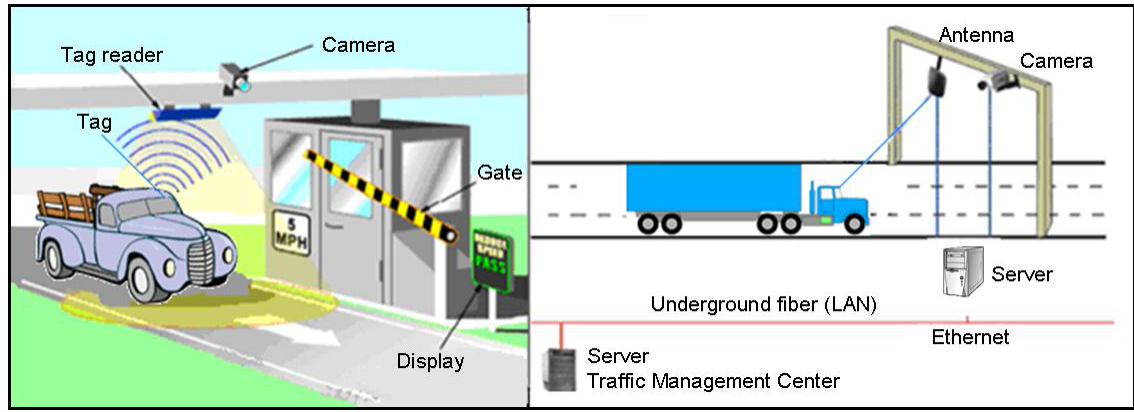

Figure 2: $\quad$ E-ZPass System (on the left - closed road line, on the right - open road line). Based on: http://www.garamchai.com/askadesi/ ask13.htm; http://www.calccit.org/itsdecision/serv_and_tech/ list.html

collection, information management, on-board equipment, radio beacons and other facilities.

This system, developed to improve both safety and convenience levels, not only provides accident and other travel-related data to cars driving at high speeds, it also uses the Internet to provide music and image streaming, and to reserve and pay for airline tickets.

Fiber-optic cables buried within the road are capable of detecting road surface temperatures and can issue warnings when freezing conditions exist.

An image recognition system monitors your car as you drive to detect possible danger signs. It offers the driver information on the possible existence of dangerous situations, and provides information on safer driving to avert such dangers.

Microwave-based digital short range communication (DSRC) systems need road-side equipment, typically mounted on a gantry, with electronic tags in the vehicles which may be read-only, read-write or smartcard-based. The majority of systems all over the world have tags reading-only, contain a fixed identification code which, when interrogated by a roadside reading device at the charging point, conveys this identity to the roadside system.

\subsection{GPS/GSM based tall collection systems}

Hitachi telematic system was implemented in Japan in 2001 for managing of transport companies [7]. It functions based on GPS, GSM communication and Internet. Each vehicle is equipped with digital tachograph, OBU and telematic terminal, which uses GPS to measure its current position and reports it to an application service provider (ASP) center at regular intervals (usually every 15 minutes) via a mobile packet transmission network. A PC (personal computer) at the transportation company's office can be connected to the ASP center via the Internet, and can be used to display the current position and route of each vehicle superimposed on a map of Japan. The vehicles are fitted with 
telematic equipment, GPS systems, packet cell phone terminals, etc., and thus have the potential to be used as floating cars.

Japan has started a new project of Quasi-Zenith Satellite System (QZSS) in FY2003 [8]. QZSS consists of three satellites and will provide a regional satellite positioning service as well as communication and broadcasting services. Each satellite is in three different orbit planes, which are obtained by inclining the geostationary orbit (GEO) by about 45 degree.

Taiwanese telematic system has the same structure as Hitachi one. It is capable of calculating and collecting road use charges via OBU and GPS. Furthermore it allows Baoruh Digital Tachograph to send vehicle status and position to the backend server via GSM/GPRS, while the server is capable of issuing commands or system parameters simultaneously [9].

In January 2005 the Toll Collect system was introduced on the $12000 \mathrm{~km}$ of German highways for all trucks with a maximum weight of $12 t$ and above. Its technology is based on the GPS, and a web application (GSM). System is capable of calculating and collecting road use charges based on the distance travelled. In addition, the Toll Collect system ensures that the collection of road tolls does not disrupt traffic flow. In contrast to conventional toll systems, Toll Collect does not require vehicles to slow down or stop, or restrict them to a designated lane [10].

The main element of the automatic log-on system is the On-Board Unit [11]. OBU is used for positioning, monitoring and billing. With the aid of GPS satellite signals and other positioning sensors, the OBU automatically determines how many kilometers have already been driven on the toll route, calculates the toll based on the vehicle and toll rate information that has been entered, and transmits this information to the Toll Collect computer centre for further processing. Additionally the OBUs have infrared interfaces for communicating with stationary control bridges on the motorways. System has 300 gantries equipped with IR detection equipment and high resolution cameras able to pick out trucks via profiling (and record number plates). Toll Enforcement will also rely on mobile patrols, consisting of a fleet of 300 vehicles with 540 officers of the Federal Office of Freight (BAG). The officers will patrol the autobahns, checking vehicles and drivers to see if they have paid the toll or have the OBU installed (these vehicles will be equipped with an infrared short range DSRC (Dedicated Short Range Communications) system that can be used to scan and monitor trucks in motion). The BAG will have police powers to request trucks to stop for examination at any point during their journey.

The OBU will also be able to work with the new Galileo satellite system for positioning which is being developed in Europe as a more accurate alternative to GPS.

A GSM/GPS system for road charging has been made a long-term government target in the UK. This technology is the only ETC system that can also potentially support telematics services, including the e-call provision that the EC would like to see introduced for all new cars from around 2010. 
The European Commission argues that satellite positioning in conjunction with mobile communications is the only solution that allows easy application of 'zone tolls'- within conurbation, for example.

\section{System proposal for Poland}

The Motor Transport Institute with the University of Technology in Warsaw and Lublin had intend to create the structure of The National Automatic Toll Collection System for Poland (NATCS). System will consist of The National Automatic Toll Collection Center (NATCC), control gates and on-board units (OBU) - fig.3.

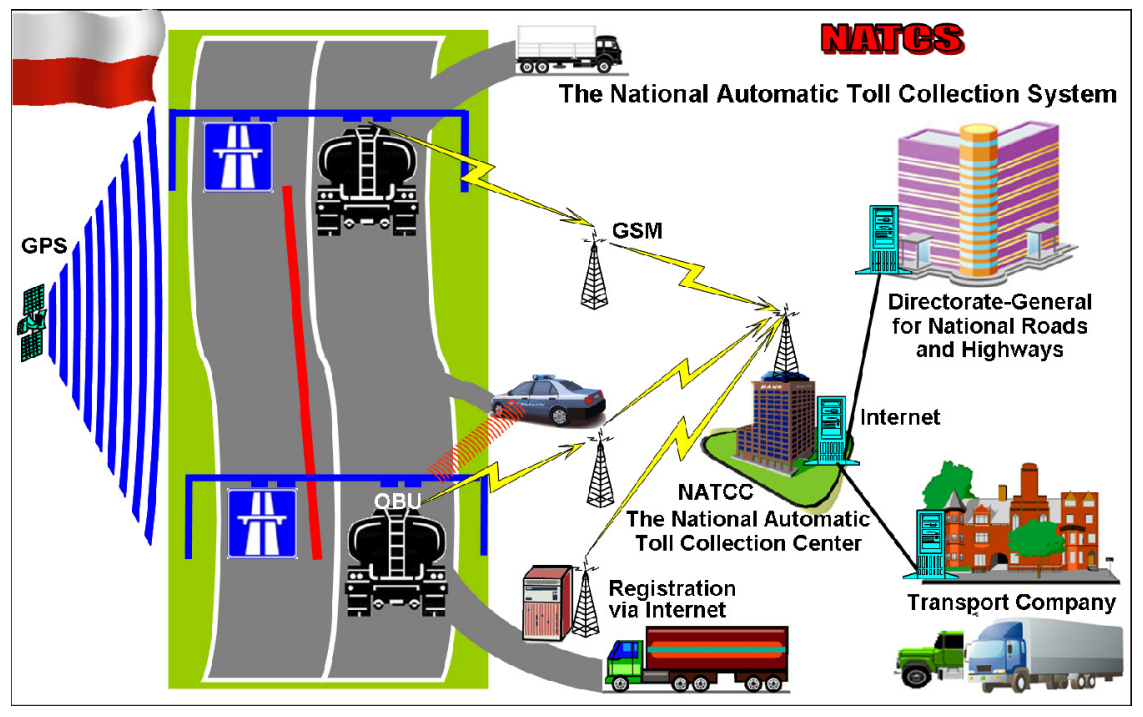

Figure 3: The structure of the National Automatic Toll Collection System (NATCS).

The prototype of control gate and OBU will be manufactured by AutoGuard S.A. It is a leading company on the Polish market that has produced telematics systems since 2000. Its experience is based on long-term cooperation with scientific and research institutes as well as on continuous analysis of new technologies that allow creating new telematics solutions.

The system is based on an innovative combination of mobile telecommunications technology (GSM) and GPS, the satellite-based Global Positioning System. The main element of the automatic log-on system is the OnBoard Unit (OBU). With the aid of GPS satellite signals and other positioning sensors, the OBU automatically determines how many kilometres have already been driven on the toll route, calculates the toll based on the vehicle and toll rate information that has been entered, and transmits this information to the NATCS computer centre for further processing. 
Software will be supported with electronic road maps and data of users registered as well as data charges of highways and expressways.

Charge counting will start after highway entrance gate and finished after highway exit gate. Data on vehicle position will be additionally approved by GPS system and delivered to NATCC by GSM net. The toll amount is based on the truck's emission category and number of axles, as well as on the length of the toll route.

For truck drivers, automatic log-on requires the least amount of effort: He is not required to book the route himself. All key data is already stored in the OnBoard Unit. The prerequisite for participating in automatic log-on is registration of the transport company and the trucks with General Directorate-General for National Roads and Highways (DGNRH) and toll payment to DGNHR. After registration, the company receives a vehicle card for each truck. This card contains the most important vehicle information. With this vehicle card, the user can schedule an appointment with an authorized Toll Collect Service Partner to have an On-Board Unit installed.

The simplest way to pay the truck toll is to register the company and vehicles with DGNHR. A registered user can have an On-Board Unit installed and participate in automatic log-on and use all possible means paying the toll (credit account, credit card or fuel card, cash payment). Immediately after registering your company, the transport company will receive a personal user number and a master PIN number for security. After vehicle registration, Toll Collect Service Partner will send the transport company a vehicle card for each truck, containing the most important information about the vehicle.

System has control gates equipped with IR detection equipment and high resolution cameras able to pick out trucks via profiling (and record number plates) - fig 4.

Toll enforcement and the punishment of violations are the responsibility of the Road Transport Inspection. The RTI has provided the technology needed for an effective enforcement system so that RTI can enforce correct booking of the toll, thereby ensuring that all toll payers are treated equally. With the aid of this system, RTI can determine if a vehicle has an obligation to pay toll and if it has met this obligation fully, partially, or not at all.

The control system distinguishes between automatic enforcement through control gates, enforcement by stationary and mobile teams, and company-level enforcement. This combination guarantees comprehensive, continuous enforcement of the requirement to pay toll and allows the control system to be constantly adjusted to meet prevailing circumstances.

\section{Conclusions}

These two families of technology for future electronic toll collection systems all have different attributes, advantages and disadvantages. For many years, microwave-based digital short range communication (DSRC) systems have been preferred, due to their simplicity of operation, potential for supporting additional services for vehicle users and, most importantly, because they are easy for users 
to understand. These systems need roadside equipment, typically mounted on a gantry, with electronic tags in the vehicles which may be read-only, read-write or smartcard-based. The key limiting factor seems to be the processing speed of the smartcard - each charging point has two gantries - one to start communications with the vehicle and a second (further down the road) to complete the transaction and perform enforcement measures, if necessary.

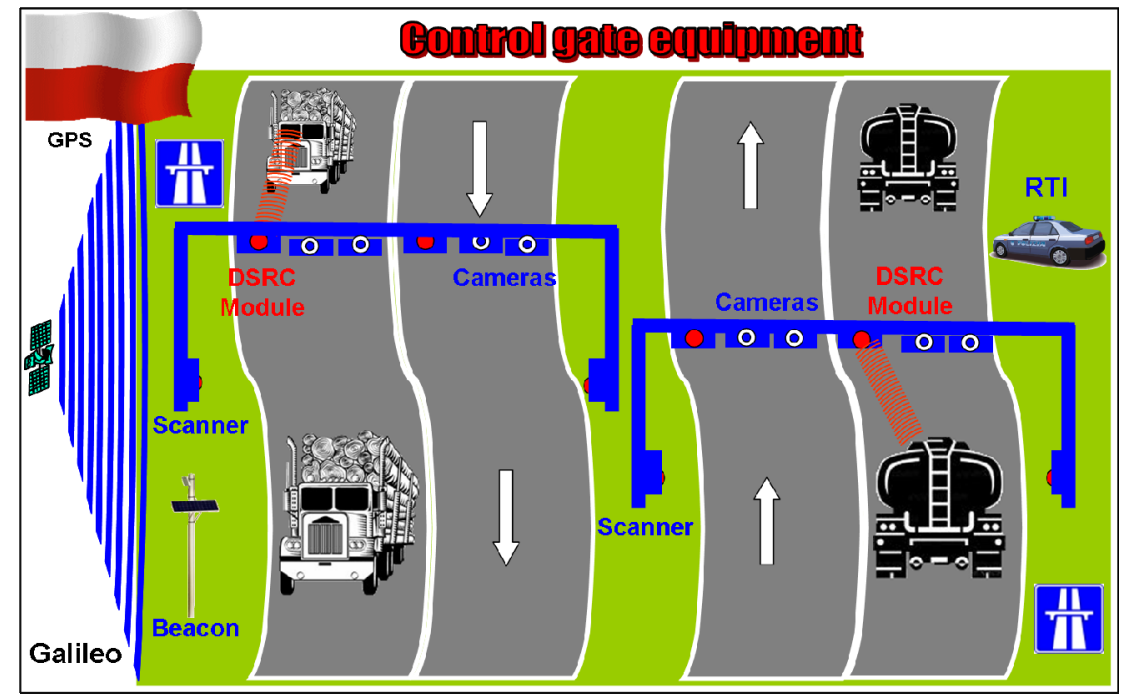

Figure 4: Control gate with other electronic equipment.

A new class of ETC systems is based on a combination of mobile communications technology (GSM) and the satellite-based global positioning system (GPS). An innovative element of the automatic log-on system is the OnBoard Unit (OBU), which automatically calculates the amount of charge due and takes into account the emissions class (ecological aspect) and the number of vehicle axles in calculating this charge. The first GPS based system advantage is an absence of the need for new road infrastructure (gantries), while the operators can keep using the existing infrastructure. System works without toll booths, extra lanes, speed restrictions or complex structures along toll roads. The second one is much greater flexibility in defining or changing payment by simply redefining the "virtual" toll areas. It means the ability to adapt easily and quickly to changes in charge parameters (road classes, vehicle types, emission levels, times slots etc). The third is the systems ability to support other value-added services on the same technology platform. These services might include fleet and vehicle engine management systems, emergency response services, pay-as-youdrive insurance services and navigation capabilities.

With regard to future expansion and development, the satellite-based toll collection system will be a better solution, especially with regard to flexibility when it comes to extending toll collection to every road category, every category 
of vehicle and, what's more, in terms of cost efficiency in implementation and operation.

\section{Acknowledgement}

This work has been supported by research project - NATCS N R10 000104.

\section{References}

[1] Directive 2004/52/EC of the European Parliament and of the Council of 29 April 2004 on the interoperability of electronic road toll systems in the Community. OJ of the EU, L 166/132, 30.04.2004.

[2] The Act from 7 of November 2008 on changing act of public roads and some other acts. Official Journal 2008, No 218, position 1391.

[3] Beckers T., Brenck A., Klatt J. P., Die ASFINAG und das Österreichische Modell der Fernstrassenfinanzierung Finanzierung des Netzes durch die Autobahnen- und Schnellstrassen-Finanzierungs-AG als privatrechtliches Unternehmen. Internationales Verkehrswesen, Nu 1+2. Hamburg, 2006.

[4] Hofstetter H., Electronic Tolling System in Austria. Conference on Road Charging. Paris, 1 June 2006.

[5] Burris M.W., "Electronic Toll Collection and Variable Pricing". Chapter 10 in Assessing the Benefits and Costs of Intelligent Transportation Systems. Volume 10 of Transportation Research, Economics, and Policy. Kluwer Academic Publishers, San Antonio, 2004.

[6] Electronic Toll Collection/Electronic Screening Interoperability Pilot Project Final Report Synthesis. Department of Transportation, Publication FHWA-OP-03-XXX, USA, July 29, 2005.

[7] Gommori N., Fushiki T., Ito A., Nakagawa H., Nitta T., Telematics Information Service for Commercial Vehicles (B2B) - Hitachi's ASP Service for Truck Fleet Management. Hitachi Review Vol. 52, No. 1, 2003.

[8] The materials of 16th meeting of the CCTF Quasi-Zenith Satellite System a new satellite positioning system of Japan - Communications Research Laboratory, Koganei, Tokyo, Japan, 1-2 April 2004.

[9] Shou-Ren $\mathrm{Hu}$, Realization of ITS Potentials and Benefits - From the Current to the Future ITS Development and Deployment in Taiwan. ITS Academia Network Symposium. Keio University, Yokohama, Japan, June 13, 2002.

[10] Kossak A., Road Pricing in Germany. Research and Consulting. Hamburg. TRB 2006 Annual Meeting. Washington D.C. January 22 -26, 2006.

[11] LKW-MAUT Electronic Toll Collection System for Heavy Goods Vehicles, Germany, http://www.roadtraffic-technology.com/projects/lkwmaut/lkw-maut4.html. 